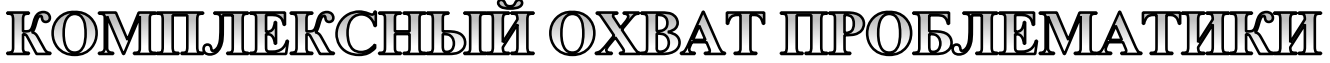

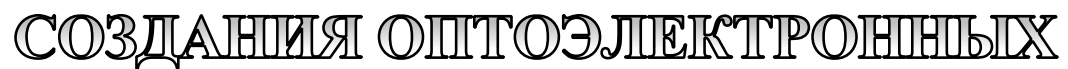

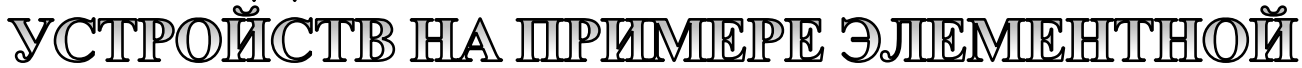

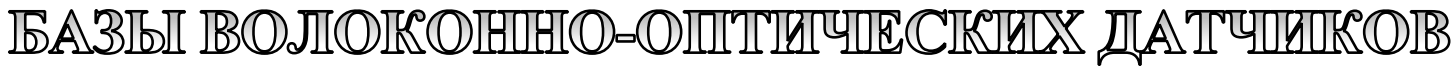

\begin{abstract}
М.Е. Белокрылов, Пермский федеральный исследовательский иееттр УрО РАН
А.И. Кривошеев, Пермский федеральный исследовательский иентр УрО РАН; Пермский национальный исследовательский политехнический университет К.П. Латкин, Пермский федеральный исследовательский ичентр УрО РАН; Пермский национальный исследовательский политехнический университет Ф.Л. Барков, Пермский федеральный исследовательский изентр УрО РАН В.В. Бурдин, Пермский федеральный исследовательский иентр УрО РАН; Пермский национальный исследовательский политехнический университет Ю.А. Константинов, Пермский федеральный исследовательский иентр УрО РАН

Р.С. Пономарев, Пермский федеральный исследовательский иентр УрО РАН;

Пермский государственный национальный исследовательский университет
\end{abstract}

Приведены основные результаты исследований авторского коллектива за последнее время. Сделан акцент на рассмотрение общих принципов, доступных для понимания широкому кругу читателей, исследования актуальных задач в области волоконно-оптических датчиков и методов контроля элементов и базовых устройств оптоэлектронной промышленности. В частности, кратко рассмотрены методы контроля производства активных волоконных световодов на этапе заготовки и после вытяжки волокна, а также метод более точного определения положения пика бриллюэновского рассеяния в случае коротких зондирующих импульсов.

Ключевые слова: рефлектометрия, фотоника, распределенные датчики, волоконные датчики, интерферометр Маха-Цандера, активные оптические волокна, сенсорика, импульсный лазер, бриллюэновский сдвиг, рассеяние Рэлея.

\section{Введение}

Оптоэлектронные устройства за последние десятилетия стали незаменимыми составными частями и самостоятельными инструментами в современной науке и технике. Стабильность функционирования таких устройств напрямую зависит от качества и эксплуатационных характеристик их элементов: оптических волокон разных типов и реализованных на них делителей, поляризаторов, оптиче- ских усилителей, фильтров и т.д., интегрально-оптических схем и созданных на их базе модуляторов амплитуды и фазы, а также других, не менее важных элементов. Ввиду этого необходимо постоянно создавать научные основы методов исследования подобных компонентов на трех стадиях: стадии изготовления, паспортизации готового элемента и, разумеется, на стадии интеграции и использования в уже готовом оптоэлектронном устройстве. 
Одно из самых динамично развивающихся направлений оптоэлектроники точечные, распределенные и квази-распределенные волоконно-оптические датчики [1]. На примере указанного направления хорошо видны ключевые критерии развития данного научно-технического сегмента: оптимальные показатели сенсора (телекоммуникационного или специального оптического волокна), стабильность активных и пассивных элементов блока опроса (модуляторов, усилителей, реализованных на активных волоконных световодах и других составных частей). Конечно же, самые главные и до сих пор эксплуатируемые методы исследования упомянутых блоков появились достаточно давно, однако постоянно растущие требования к системам проецируются и на указанные выше элементы. В условиях научной и коммерческой конкуренции, на фоне нестабильной геополитической ситуации крайне желательно поддержание отечественной оптоэлектронной базы для сенсорики и иных применений на конкурентном уровне.

\section{Проблематика}

Рассмотрим типовую упрощенную схему распределенного волоконно-оптического датчика на основе оптического рефлектометра Рэлея. В его состав входит когерентный лазерный источник излуче- ния с модулятором интенсивности. Также в нем присутствует оптический (иногда перестраиваемый) фильтр, входной и выходной усилитель на эрбиевом активном волокне, разветвитель, сенсорное волокно. Для наглядности все упомянутые элементы занесены в таблицу.

Очевидно, что источник излучения является основой всей системы. Стабильность источника излучения можно достаточно просто изучить его временной прописью (фиксированием мощности во времени) в варьирующихся и/или стабильных условиях, длину когерентности в случае узкой спектрально полосы не удастся зафиксировать методами традиционного спектроанализа или спектрометрии, но для этого существуют специальные интерферометры.

Не так все однозначно с модулятором интенсивности. В случае, когда он организован на основе интерферометра МахаЦендера, одной из его отличительных особенностей может быть локальное скопление зарядов вблизи волновода, вызывающее быстрое прекращение каналирования на резких температурных перепадах. Однако эта задача уже активно рассматривается коллективом авторов [2-4].

Следующий элемент - оптический фильтр. Как показали температурные исследования, оптический фильтр достаточно хорошо сохраняет форму спектра до

Таблиияа

Элементы распределенного волоконно-оптического датчика

\begin{tabular}{|c|c|c|c|c|}
\hline Элемент & Базовый элемент & $\begin{array}{l}\text { Ключевые } \\
\text { параметры }\end{array}$ & $\begin{array}{l}\text { Критерий } \\
\text { важности }\end{array}$ & Примечание \\
\hline \multirow{3}{*}{$\begin{array}{c}\text { Передающий } \\
\text { блок }\end{array}$} & Источник излучения & $\begin{array}{l}\text { Стабильность, } \\
\text { когерентность }\end{array}$ & Высокая & - \\
\hline & $\begin{array}{c}\text { Модулятор } \\
\text { интенсивности }\end{array}$ & $\begin{array}{c}\text { Экстинкция } \\
\text { импульсов, } \\
\text { стабильность } \\
\end{array}$ & Высокая & - \\
\hline & Фильтр & $\begin{array}{c}\text { Полоса пропускания, } \\
\text { стабильность }\end{array}$ & Средняя & $\begin{array}{c}\text { «Средняя» важность } \\
\text { обусловлена } \\
\text { возможностью } \\
\text { компенсации дрейфов. }\end{array}$ \\
\hline $\begin{array}{l}\text { Оптический } \\
\text { усилитель }\end{array}$ & $\begin{array}{c}\text { Активное оптическое } \\
\text { волокно }\end{array}$ & $\begin{array}{c}\text { Эфррективность / } \\
\text { цена }\end{array}$ & Высокая & 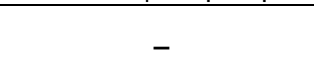 \\
\hline Сенсор & $\begin{array}{c}\text { Телекоммуни- } \\
\text { кационное или } \\
\text { специальное } \\
\text { оптическое волокно }\end{array}$ & $\begin{array}{l}\text { Равномерность, } \\
\text { низкие потери, } \\
\text { специальные } \\
\text { свойства }\end{array}$ & Высокая & - \\
\hline
\end{tabular}


самых незначительных деталей в широких температурных диапазонах, однако почти во всех своих исполнениях от внешних условий зависима его центральная длина волны [5]. Практический опыт применения таких фильтров говорит о возможности термокомпенсации характеристик, именно поэтому в таблице важность соблюдения исходных характеристик оценена как «средняя».

Роль оптических волокон, легированных ионами эрбия, и усилителей на их основе переоценить сложно.

Обычно в эрбиевых усилителях применяются бухты активных волокон порядка единиц или десятков метров. Изучение оптических параметров на этапе производства волокон включает несколько этапов. Так, распределение активного редкоземельного металла в преформе активного световода производят при помощи специального анализатора, осуществляющего пространственное сканирование диодом накачки на длине волны вблизи длины волны накачки [6]. После вытяжки осуществляется разделение световодов на участки, и каждый из участков исследуется спектрально.

Также изучаются другие оптико-геометрические параметры волокон. Величина, которая не измеряется напрямую в лаборатории - действительная протяженность волокна. Ориентирами при паспортизации данного параметра обычно являются счетчик метража приемного устройства на башне вытяжки волокна и расчет-

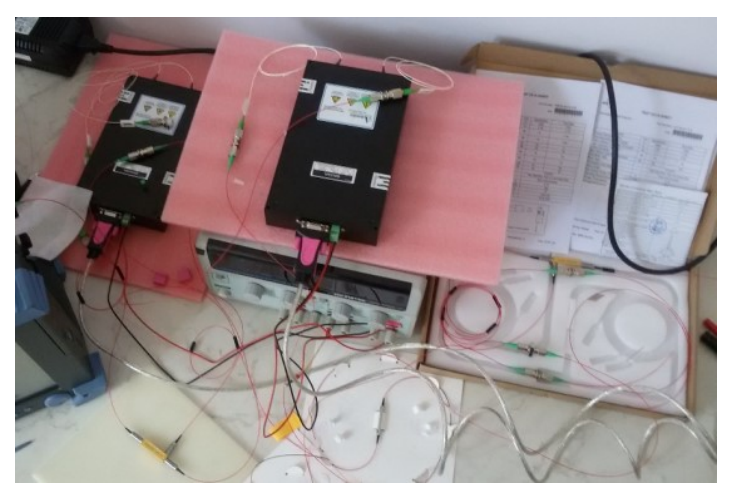

Рис. 1. Оптический усилитель и оптический предусилитель в составе макета рэлеевского рефлектометра ные величины длины световода, полученные из параметров заготовки. Фактическое время запуска счетчика метража в условиях различного времени выхода процесса на режим может определяться и человеческим фактором - особенно, если речь идет об экспериментальных конструкциях световодов.

Далее активный волоконный световод, длина которого, возможно, неточно зарегистрирована, поступает на производство волоконных лазеров или усилителей. В различных оптоэлектронных устройствах используется разная длина активного волокна, зачастую она подбирается экспериментально, а значит - каждый раз отматывается с запасом. Регламентировать как сам такой запас, так и способ его фактического контроля для каждого исследователя достаточно сложно. Это может привести к тому, что с учетом всех ранее упомянутых факторов информация о длине световода, хранящегося на складе, уже после 50-70 отмоток с нескольких километров волокна накапливает достаточно весомую ошибку: в единицы, а иногда в десятки метров.

Несложно оценить, что при рыночной стоимости активного эрбиевого волокна от 20 до 100 долларов США за 1 метр описанные неточности приобретают и финансовую важность. Необходимо при этом оценивать и качество оставшегося волокна - имеет ли оно ощутимые отклонения оптико-геометрических параметров по длине [7]. Именно для этой цели был разработан полностью волоконный рефлектометр, призванный стать второй стадией контроля оптических волокон, легированных ионами эрбия. Об этом подробно рассказано в следующем разделе.

Сенсор распределенного датчика также является важным элементом. Если оптические потери - тот показатель, который для типовых оптических волокон и многих специальных световодов уже в достаточной степени оптимизирован и контролируется хорошо известными и внесенными в Госреестр средствами рэлеевской рефлектометрии, то равномерность в ряде случаев контролировать приходится особыми 
способами. Особенно это актуально для специальных волоконных световодов и/или волокон, вмонтированных в объект исследования. Эффекты пережатий, полимеризация клея, смол, затвердевание бетона и прочие процессы могут создавать в волоконных световодах механические напряжения, которые не видны на типовом рефлектометре. В таких случаях уместно применение бриллюэновских рефлектометров [8]. Однако если сенсор не слишком протяженный, появляется необходимость уменьшать продолжительность зондирующего импульса. При подобном зондировании спектр бриллюэновского рассеяния может сколько-то отличаться от функции Лоренца, а значит, типовой метод определения максимума бриллюэновского спектра может давать неточные результаты. Именно поэтому был разработан метод обратной корреляции бриллюэновского спектра [9].

\section{Контроль качества активных волоконных световодов}

По факту, контроль качества изделий возможен при разработанном инструментарии на нескольких стадиях: при необходимости могут быть исследованы содержащие активный эрбий образцы, не имеющих типичную форму заготовки оптоволокна. Так, на рис. 2 показано исследование стеклянного шаpa, содержащего активный эрбий. Розовое свечение на фото (видно в цвете) обусловлено люминесценцией образца, захваченной видеокамерой. На следующей стадии (рис. 3) возможно проведение измерений преформ.

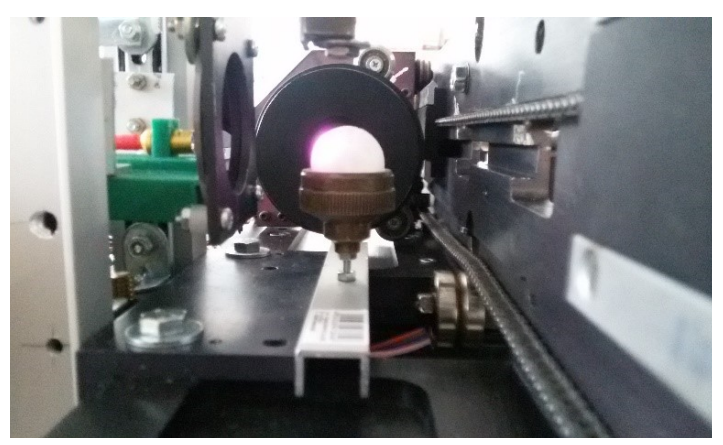

Рис. 2. Исследование образиа с активным эрбием

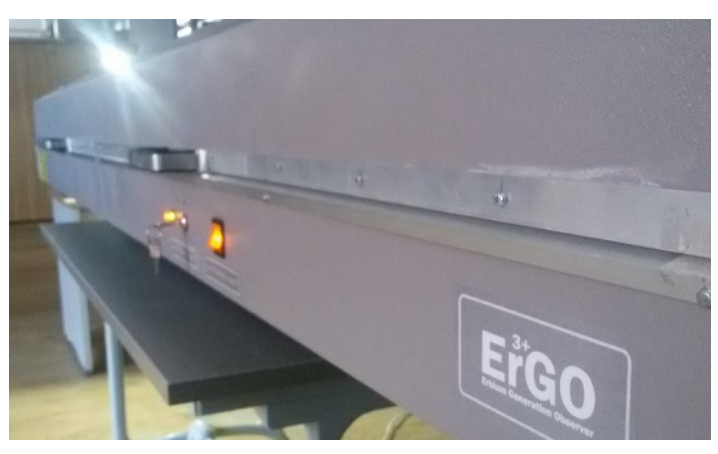

Рис 3. Разработанный авторами анализатор в прочессе измерения преформы активного волоконного световода (режим работы источника излучения накачки позволяет сделать фото только с закрытой крышкой)

Подробнее о принципах и особенностях работы анализатора ErGO можно узнать в [6]. После изготовления преформы, как было отмечено выше, она поступает на вытяжку. Для контроля параметров активных волоконных световодов необходимо было создать специальное устройство [7]. Разумным и не самым ресурсозатратным выходом может быть применение импульсного волоконного источника с пассивным затвором [10, 11]. Использование полностью волоконного рефлектометра (за исключением регистрирующих устройств) позволяет создать достаточно простое устройство без использования большого числа внешних электронных устройств (драйверов, генераторов, согласующих схем). Подробная схема, принцип работы и методика проведения исследований можно описана в [7]. Сконструированное устройство помогло эффективно определять длину активного волокна (рис. 4) на расстояниях, превышающих возможности типовых рефлектометров,

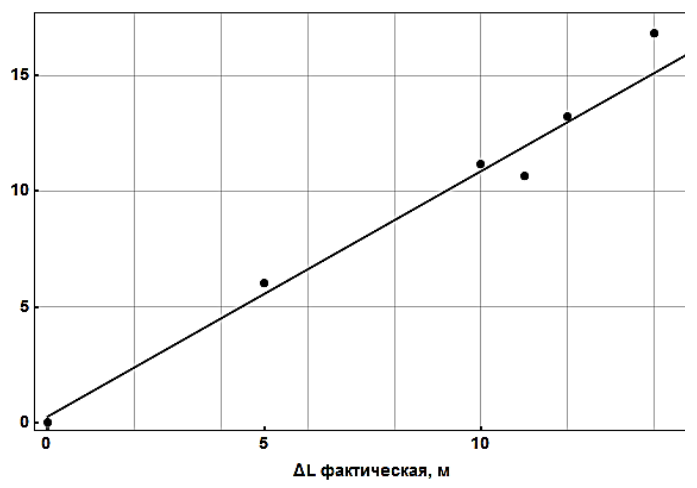

Рис. 4. Сопоставление фактического и измеренного укорочения длинь волокна [7] 
что является важным аспектом его эффективного изготовления, а значит - одним из способов уменьшения цены. К тому же, данная установка на начальном уровне определяет равномерность волокна, что важно, когда его конструкция усложнена, например, специальными стержнями (сохраняющее поляризацию волокно).

\section{Оптимизация сенсора распределенного датчика}

Оптимизировать что-либо невозможно без получения актуальной информации об объекте изучения. Как было отмечено выше, оптимизация бриллюэновского рефлектометра приводит к новой задаче действительного нахождения максимума бриллюэновского рассеяния в каждой точке сенсора. Авторы предлагают использовать корреляционный анализ для дальнейшего повышения достоверности детектирования максимума бриллюэновского спектра [9]. Эффективность использования корреляции для пост-обработки рефлектометрических данных уже была доказана в [12]. Аппаратно-реализованный алгоритм корреляции достаточно хорошо изучен и оптимизирован под вычисления в реальном времени, в том числе и в области оптической рефлектометрии [13]. Корреляционный анализ требует наличия двух функций, одну из которых в данном случае целесообразно получить разворотом исходного спектра (рис. 5).

Предложенный метод не нуждается в поступлении новых данных извне (второ-

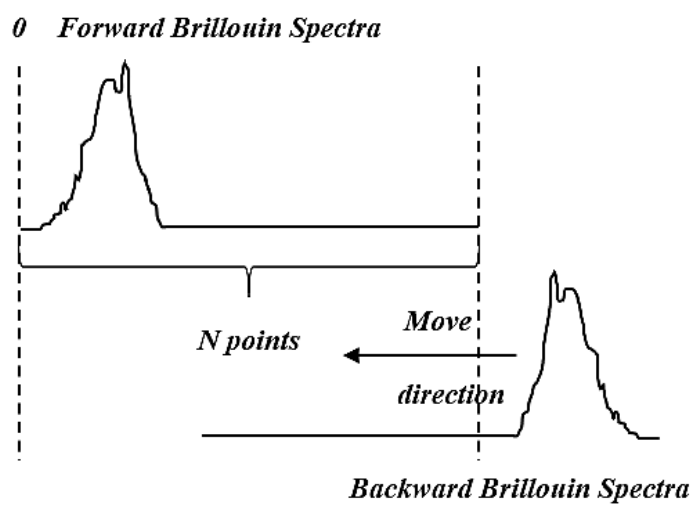

Рис. 5. Принциип работы метода обратной корреляции бриллюэновских спектров го спектра); в случае наличия шумовых неоднородностей, приводящих к асимметрии бриллюэновского пика, в некоторой степени устраняет их на итоговой корреляционной функции. Случайные шумы спектра, перезаписанные в обратном порядке, дают близкую к нулю корреляцию со своей исходной копией, в то время как математическая связь двух лоренцевых распределений на этом фоне выглядит гораздо более заметной. Практика показала, что заполнение пустых отсчетов при «движении» одной дискретной функции относительно другой целесообразно осуществлять случайными значениями из шумовых областей спектра. После построения взаимно-корреляционно функции целесообразно нахождение максимума при переборе отсчетов с двух сторон с последующим вычислением среднего значения.

Моделирование показало, что метод сравним на длинных импульсах с методом масштабирования аналитически заданной лоренцевой функции, применяемым во всем мире и, по прогнозам, должен быть более эффективен на коротких зондирующих импульсах. Также в эксперименте и моделировании было показано доминирование метода над типовой процедурой «FindMax» (нахождение максимального дискретного спектрального значения методом перебора).

\section{Будущая работа}

Очевидно, что продемонстрированные вновь разработанные и модифицированные методы получения новой информации из бриллюэновского спектра (как разделенные температуры и деформации, так и уточненное значение бриллюэновского сдвига) должны в дальнейшем получить развитие. Уместным будет совершенствовать те отличительные особенности методов, которые при первичном сравнении с аналогами вызовут наибольший интерес. В частности, напрашивается детальное сопоставление с широко используемым методом масштабирования аналитически заданной лоренцевой функции, особенно при 
зондировании короткими импульсами (в этом случае спектр может существенно отличаться от лоренцевой формы, что делает ранее используемые методы неприменимыми). Идеальным было бы сравнение оригинальных методов обработки на базовых алгоритмах и одних и тех же исходных данных, что становится возможным в рамках взаимодействия различных научных групп, являющихся авторами описанных методов. В отсутствие таких возможностей уместно повторение известных методов по информации, представленной в литературе, и/или временное смещение акцента исследования к адаптации метода под нахождение распределенного двулучепреломления РМи иных волокон и разделению температур и деформаций в них.

Что касается исследования активных волокон, то несложно заметить, что создание полностью волоконного рефлектометра для тестирования протяженных участков высоколегированных эрбиевых световодов может получить развитие в тестировании и других элементов, окна прозрачности которых находятся в отличных от полутора микрон областях. Планируется также апробация разработанных методик и для интегрально-оптических схем (с переносом в частотную область, для повышения пространственного разрешения). Метод тестирования преформ активных волоконных световодов требует стабилизации точности полученных результатов.

Очевидно, что применение новых методов привносит и будет привносить синергетический эффект в дальнейшем. Это обусловлено, во-первых, тем, что действие методов направлено на один и тот же объект, и разные методы, после некоторых модификаций, могут быть направлены на решение задач других составных частей объекта. Во-вторых, оптическая рефлектометрия в ближайшие десятилетия имеет все возможности стать методом «самоконтроля». О том, что одни рефлектометры исследуют оптические схемы других, известно уже не из научных статей, а из технических спецификаций серийных приборов. Поэтому принцип, схожий с принципом «роботы делают роботов» может сработать и выродиться в эффект снежного кома, когда рост оптоэлектронной отрасли станет лавинообразным.

\section{Библиографический список}

1. Yi Bao, Ying Huang, Matthew S. Hoehler and Genda Chen / Review of Fiber Optic Sensors for Structural Fire Engineering / Sensors 2019, - Vol. 19. № 4. - P. 877; DOI.org/10.3390/s19040877

2. Программно-аппаратный комплекс получения и обработки оптических рефлектограмм интегральнооптических схем в частотной области / Д.И. Шевцио, Р.С. Пономарев, Ф.Л. Барков, С.Д. Бочкова, Д.Б. Владимирова, Ю.А. Константинов // Фотон-Экспресс. - 2019. - № 6(158) : спец. вып. Фотон-ЭкспрессНаука, 2019: ВКВО 2019: конф., посвящ. памяти акад. Е.М. Дианова. - Пермь, 2019. - С. 322-323.

3. Шевциов Д.И., Константинов Ю.А., Белокрылов М.Е., Пономарев Р.С. / Оптимальные параметры сбора данных при температурном исследовании интегрально-оптических модуляторов методом рефлектометрии частотной области / Вып. \#3/2020 / DOI: 10.22184/2070-8963.2020.88.3.48.53

4. Ponomarev R.S.; Shevtsov D.I., Karnaushkin P.V. «Shutdown» of the Proton Exchange Channel Waveguide in the Phase Modulator under the Influence of the Pyroelectric Effect. // Appl. Sci. - 2019. № 9. - P. 4585.

5. Белокрылов М.Е., Оглезнев А.А., Константинов Ю.А. Исследование параметров перестраиваемого фильтра Фабри-Перо в условиях частотного сканирования в широком температурном диапазоне // Фотон-Экспресс. - 2019. - № 6 (158) - C. 332-333, DOI: 10.24411/2308-6920-2019-16173.

6. Konstantinov Yu.A., Latkin K.P., Barkov F.L., Smirnov A.S., Poskrebyshev M.M., Pervadchuk V.P., Vladimirova D.B., Konin Yu.A., Garanin A.I., Burdin V.V. / Special Optical Fiber Preform Layers 3DReconstruction / November 2017 Scientific Visualization 9(4):47-58 / DOI: 10.26583/sv.9.4.05

7. Belokrylov M.E., Konstantinov Y.A., Latkin K.P. [et al.] An All-Fiber Time Domain Reflectometer for Measuring the Length of Active Erbium Doped Optical Fibers. // Instrum. Exp. Tech. - 2020. - Vol. 63. P. 481-486. https://doi.org/10.1134/S0020441220050012.

8. Xiaoyi Bao, Liang Chen (2005). Development of the Distributed Brillouin Sensors for Health Monitoring of Civil Structures. 10.1007/978-1-4020-6952-9 5.

9. Barkov, F.L.; Konstantinov, Y.A.; Krivosheev, A.I. A Novel Method of Spectra Processing for Brillouin Optical Time Domain Reflectometry. // Fibers, - 2020. - № 8. - P. 60.

10. Kurkov A.S., Sholokhov E.M., Medvedkov O.I. AH fiber Yb-Ho pulsed láser. // Laser Phys. Letters. - 2009. № 6. - P. 135. 
11. Курков А.С., Шолохов Е.М. Импульсный волоконный Yb:Но лазер. // 3-го Российского семинара по волоконным лазерам. - Уфа: Сб. тр. - 2009. - С. 54-55.

12. Konstantinov Yu.A., Kryukov I.I., Pervadchuk V.P., Toroshin A.Yu. Polarisation reflectometry of anisotropic optical fibres // QUANTUM ELECTRON. - 2009. - Vol. 39. - № 11. - P. 1068-1070, https://doi.org/10.1070/QE2009v039n11ABEH014171

13. Güemes A., Fernández-López A., Soller B. / Optical Fiber Distributed Sensing - Physical Principles and Applications. - 2010. - Vol. 9. - is. 3. - P. 233-245 https://doi.org/10.1177/1475921710365263.

\title{
COMPREHENSIVE OVERVIEW OF CREATION OF OPTOELECTRONIC DEVICES ON THE EXAMPLE OF THE ELEMENT BASE OF FIBER OPTICAL SENSORS
}

\author{
${ }^{1}$ M.E. Belokrylov, ${ }^{1,2}$ A.I. Krivosheev, ${ }^{1,2}$ K.P. Latkin, ${ }^{1}$ F.L. Barkov \\ ${ }^{1,2}$ V.V. Burdin, ${ }^{1}$ Yu.A. Konstantinov, ${ }^{1,3}$ R.S. Ponomarev \\ ${ }^{1}$ Institute of Continuous Media Mechanics UB RAS \\ ${ }^{2}$ Perm National Research Polytechnic University \\ ${ }^{3}$ Perm State National Research University
}

The main results of recent research by the authors are presented. The emphasis is made on the consideration of general principles of studying the urgent problems in the field of fiber-optic sensors and methods for monitoring elements and basic devices of the optoelectronic industry. In particular, the methods for controlling the production of active optical fibers at the stage of preforming and after drawing the fiber are briefly considered, as well as a method for more accurate determination of the position of the Brillouin scattering peak in the case of short probe pulses.

Keywords: reflectometry, photonics, distributed sensors, fiber sensors, Mach-Zehnder interferometer, active optical fibers, sensorics, pulsed laser, Brillouin shift, Rayleigh scattering.

\section{Сведения об авторах}

Белокрылов Максим Евгеньевич, аспирант физического факультета, Пермский государственный национальный исследовательский университет (ПГНИУ), 614990, Пермь, ул. Букирева, 15; младший научный сотрудник лаборатории фотоники, Пермский федеральный исследовательский центр УрО РАН (ПФИЦ УрО РАН), 614900, г. Пермь, ул. Ленина, 13А; e-mail: belokrylovme@gmail.com Кривошеев Антон Иванович, аспирант факультета прикладной математики и механики, Пермский национальный исследовательский политехнический университет (ПНИПУ), 614990, г. Пермь, Комсомольский пр., 29; младший научный сотрудник лаборатории фотоники, ПФИЦ УрО РАН; e-mail: antokri@yandex.ru

Латкин Константин Павлович, аспирант факультета прикладной математики и механики, ПНИПУ; младший научный сотрудник лаборатории фотоники, ПФИЦ УрО РАН; e-mail: latkin.k.p@ya.ru

Барков Федор Леонидович, кандидат физико-математических наук, доцент кафедры «Общая физика», ПНИПУ; старший научный сотрудник лаборатории фотоники, ПФИЦ УрО РАН; e-mail: fbarkov@pstu.ru

Бурдин Владислав Викторович, кандидат физико-математических наук, доцент кафедры «Общая физика», ПНИПУ; старший научный сотрудник лаборатории фотоники, ПФИЦ УрО РАН; e-mail: vlaburdi@mail.ru

Константинов Юрий Александрович, кандидат технических наук, старший научный сотрудник лаборатории фотоники, ПФИЦ УрО РАН; e-mail: yuri.al.konstantinov@ro.ru

Пономарев Роман Сергеевич, кандидат физико-математических наук, доцент кафедры физического факультета, ПГНИУ; старший научный сотрудник лаборатории фотоники, ПФИЦ УрО РАН; e-mail: rsponomarev@gmail.com 